MIDPI

MOL2NET, International Conference Series on Multidisciplinary Sciences

\title{
sciforum
}

\section{Tree Parameters retrieval and volume estimation using Terrestrial Laser Scanner: A case Study on Barkot Forest}

\author{
Rajarshi Bhattacharjee ${ }^{a}$, Subrata Nandy ${ }^{a}$, Triparna Sett ${ }^{a}$, Amitesh Gupta ${ }^{a}$ \\ ${ }^{a}$ Indian Institute of Remote Sensing, Dehradun.
}

\begin{abstract}
LiDAR is one of the fast growing remote sensing techniques. Terrestrial laser Scanner (TLS) provides precise information about forest inventory in the form of 3D point cloud. An approach to extract tree parameters: diameter at breast height ( $\mathrm{dbh}$ ) tree height and stem length followed by volume estimation has been discussed here. The area selected for the study is Barkot Forest Range in Dehradun district of Uttarakhand. The main tree species in this region are Shorea robusta (Sal), Tectona grandis (Teak), Mallotus philippensis (Indian Red Wood) and Terminalia alata (Saj). Scans were collected using Riegl vz- 400 laser scanner. Ground measurements were also recorded which included tree height and diameter at breast height (dbh). Both field measurements and TLS based computations showed excellent correlation. Forest Survey of India (FSI) in 1996 published site and species specific volumetric equations using dbh. However, three parameters: dbh, stem length and form factor have been considered in the present study. The comparative study shows excellent match between ground based measurements and TLS derived height and dbh parameters with R2 value of 0.96 and 0.98 respectively. Moreover, in respect to volume estimation, excellent correlation of 0.98 and 0.97 was achieved between the two approaches for Sal and Teak respectively. However, for Indian Red Wood, one of the estimations using FSI equation showed negative value but the present approach produced no such anomalous outcome. The reason may be attributed to the fact that FSI based volumetric equation valid only for Assam was used due to the unavailability of Barkot specific equation. Finally, volumetric equation was developed for Terminalia alata (Saj) as there is no equation available for this particular species. The study also advocates an inverse relationship between Form Factor and dbh. This new approach may prove to be indispensable for species and site specific volume estimation in near future.
\end{abstract}

Keywords: LiDAR, TLS, tree parameters, tree volume, form factor.

\section{Introduction}

Sufficient information about changes in forest canopy can be quite useful for forest monitoring. In order to prepare a high quality inventory, there are several techniques available depending on the accepted level of accuracy. However, most of the inventory techniques are dependent on field sampling. The inventory mainly consists information about tree species local and scientific name, tree 
height and diameter at breast height. There came a dramatic change in this situation in the last decade or so because of the introduction of Light Detection and Ranging (LiDAR). In excess to Airborne Laser Scanning (ALS), the use of Terrestrial Laser Scanning (TLS) is slowly but surely gaining importance in the field of forestry.

Terrestrial Laser Scanner is a ground-based, active imaging system which comprises of a rotating scanner mounted on an elevated platform. TLS instruments enable speedy collection of point clouds representing the 3-D position of the surfaces and objects in the scanner's field-of-view, including herbaceous vegetation. The instrumentation error of TLS measurements is usually negligible, and very high density collections (millimeter to a few centimeters resolution) at ranges up to hundreds of meters are often possible at little logistical expense (Bienert et al. 2007).TLS proves most useful in areas of high uncertainty and high biomass and in complex forest ecosystems where standard algometric relationships do not apply and other modeling efforts fail. In certain cases, ALS data may not be representative in high biomass forests and thus TLS becomes important (Siedel, 2011).

The most common application of TLS in forestry is in extraction of structural parameters of trees at plot level. Besides dbh and tree height, measurements of upper stem diameters, branch internodal distance and canopy dimensions can also be measured from the laser scan data. Simonse et al. (2003) and Maas et al. (2008) have used automatic techniques like Hough transformation for the retrieval of forest inventory parameters. Mann et al. (2014) derived stem location, tree height, dbh, stem density and timber volume from ground based laser scanner and reported slight underestimation in mean tree height due to canopy shadow effects and suboptimal scan sampling distribution.

This present study aims at retrieving the tree inventory parameters for Barkot Forest Range in Dehradun district of Uttarakhand. The inventory parameters taken into consideration are tree position, $\mathrm{dbh}$, tree height and stem length. Moreover, this study also lays emphasis in deriving the relationship between $\mathrm{dbh}$ and form factor. However, the present study mainly aims at deriving volumetric equations using three parameters: form factor, dbh and stem length unlike the published volumetric equations by FSI in 1996 which considers only dbh. It is noteworthy that stem length here has been referred to the portion of the tree trunk below crown level. The branches within the crown have been neglected in volume estimation in the present study.

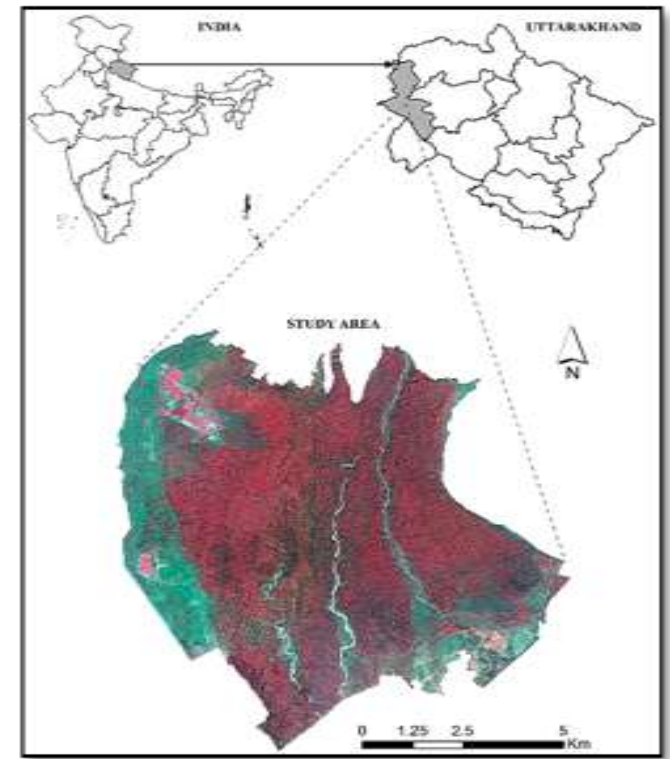

Figure 1. Overview of Barkot Forest

The area selected for the study is Barkot - Rishikesh Forest Range in Dehradun district of Uttarakhand, located between $30^{\circ} 03^{\prime} 52^{\prime \prime} \mathrm{N}$ to $30^{\circ} 10^{\prime} 43^{\prime \prime} \mathrm{N}$ and $78^{\circ} 09^{\prime} 49^{\prime \prime} \mathrm{E}$ to $78^{\circ} 17^{\prime} 09^{\prime \prime} \mathrm{E}$ (Figure 1). The study area has relatively flat, gentle and undulating terrain, lying at an elevation of 340 meters above MSL and covers an area of $84.96 \mathrm{Km} 2$. It lies in the foothills of Himalaya bounded by lesser Himalayan rocks in the north and Shiwalik in the south. It has three dry river beds passing through the center, and Chandrabagha River at the northeastern boundary which flows down to join the main Ganges. The main nearby township is Doiwala, Bhaniawala and Rishikesh. The mean annual temperature recorded in the study area with the help of Flux tower data for the year 2014-15 was $21.18^{\circ} \mathrm{C}$. The highest temperature recorded was 
$41.47^{\circ} \mathrm{C}$ and the lowest temperature was fell to $4.68^{\circ} \mathrm{C}$. Dominant tree species are Shorea robusta (Sal), Tectona grandis (Teak), Mallotus philippensis (Indian Red Wood) and Terminalia alata (Saj).

\section{Materials and Methods}

The TLS data for the study area was collected using Riegl VZ- 400 is a Terrestrial laser scanning device. Manufactured by RIEGL Company based on LiDAR technology, it provides high speed, capability to target multiple objects, non-contact data acquisition using narrow infrared laser beam and a fast scanning mechanism. The laser wavelength of the scanner in near infrared region is $1550 \mathrm{~nm}$. The scanning angle varies between -40 o to 60 o for vertical scans while the whole

Scanning range of $360 \mathrm{o}$ can be used for horizontal scans. Accuracy of around $5 \mathrm{~mm}$ can be achieved with this device for both horizontal and vertical scans.

As far as methodology is concerned, a plot of $10 \mathrm{~m}$ x $10 \mathrm{~m}$ was established, the individual trees were tagged with a number so that it becomes easy to identify the individual trees. Here, multiple scanning approach was chosen which depends on the internal forest structure of the plot. Four different scanning positions were set up: one at the center of plot and other three from different positions outside the plot. The outer scanning positions were kept at a distance of 5 meters from the boundary of the plot to capture the point cloud of the trees at the boundary also. Retro-reflectors were used as reference points for co-registration of point cloud data taken from different scanning positions.

The type of reflectors which were used were 3 circular retro-reflectors placed inside the plot, 4 strip

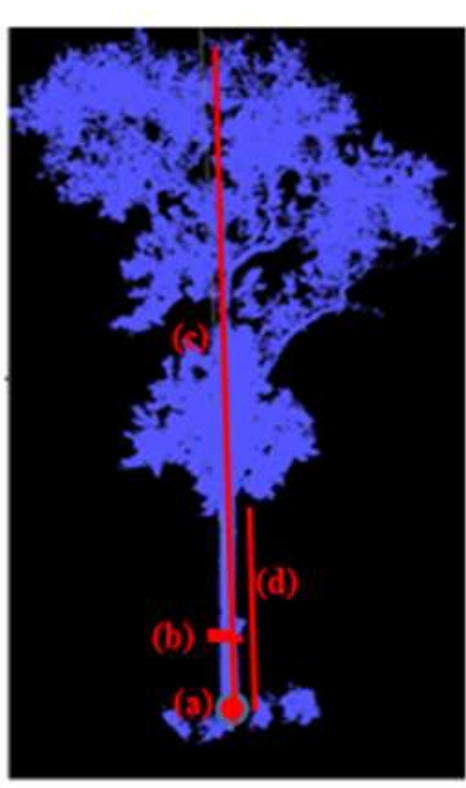

Figure 2: (a) Tree Position (b) dbh (c) Tree Height (d) Stem retro-reflectors placed at corner trees. The tie-point were placed in such a way that visibility from each scanning position is maximum. The plot was scanned from the center and three different positions outside boundary of the plot. All the four scans were registered together with each other so that they can be fitted in a proper alignment in order to give the complete structure based on point cloud data taken from different locations. The center scan was taken as reference scan and 1st scan, 2nd scan, 3rd scan were registered corresponding to each other.

The multiple scanning technique was used instead of single scan as it provides complete 3D information. The registered scans from different positions were converted to individual ASCII file (American Standard Code for Information Interchange) which were merged together using a tool in Cloud Compare. The merged scans were used to extract the plots using segmentation tool. Finally, the individual trees extracted from the plots were used for retrieval of tree parameters followed by accuracy assessment and tree volume estimation.

Table 1. TLS (Riegl VZ 400 Specifications)

\begin{tabular}{|l|l|l|}
\hline Scanner Performance & Vertical Scan & Horizontal Scan \\
\hline Scanner Angle Range & Total $100^{\circ}(+60 /-40)$ & Maximum $360^{\circ}$ \\
\hline Pulse rate & $100 \mathrm{KHz}$ & $100 \mathrm{KHz}$ \\
\hline Scan Speed & $3-120 \mathrm{lines} / \mathrm{sec}$ & $0^{\circ}-60^{\circ} / \mathrm{sec}$ \\
\hline Accuracy & $5 \mathrm{~mm}$ & $5 \mathrm{~mm}$ \\
\hline
\end{tabular}




\section{Results and Discussion}

The tree position (Figure 2. a) depicts the minimum $\mathrm{z}$ value and plays an important role in other parameters retrieval such a dbh, tree height which are dependent on minimum $\mathrm{z}$ value.

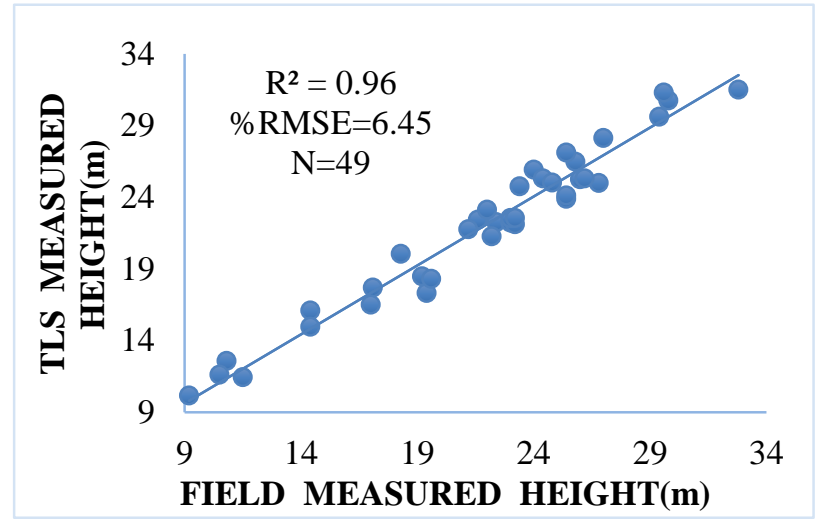

\section{Figure 3. Comparison between field} measured and TLS derived

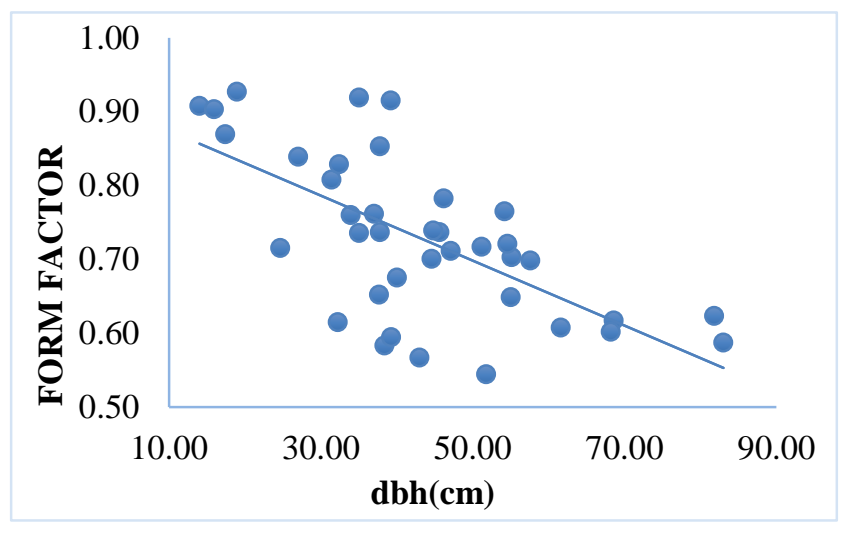

Figure 5. Inverse trend of relationship between $\mathrm{dbh}$ and form factor.

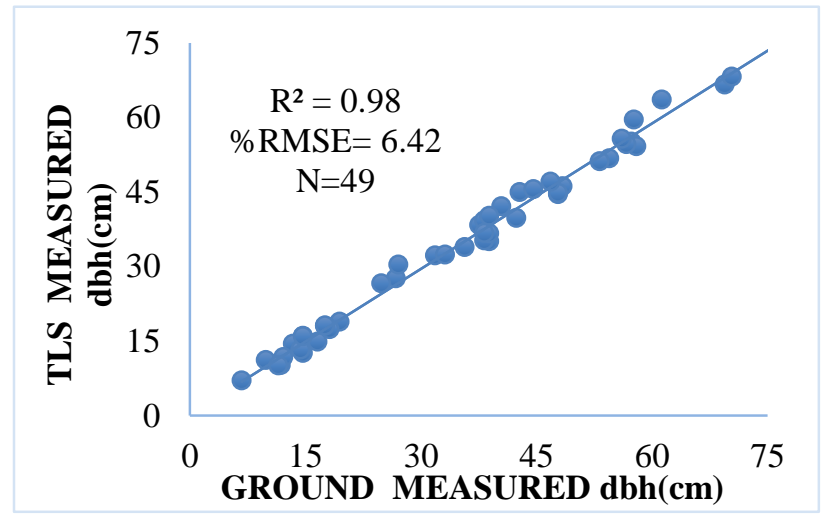

Figure 4. Comparison between field measured and TLS derived dbh

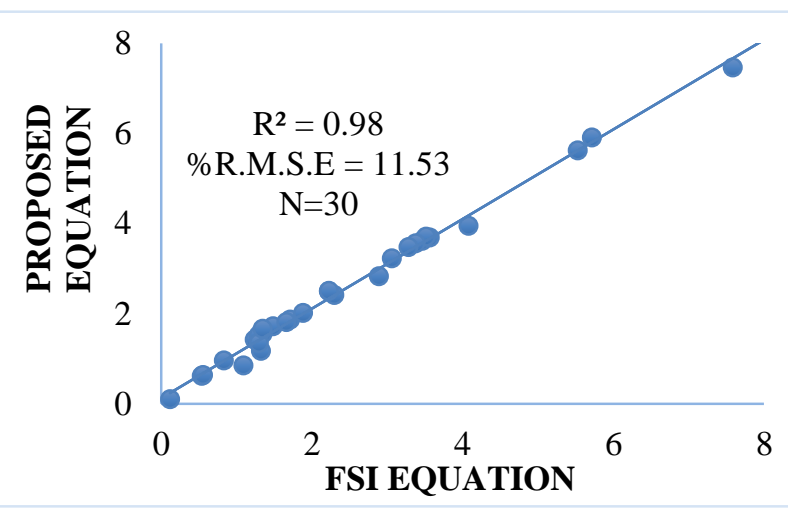

Figure 6. Comparison of Volume estimated through FSI equation \& Proposed equation for Sal.

Tree dbh (Figure 2. b) measurement is done by circle fitting technique at the height of $1.37 \mathrm{~m}$ above the minimum z-value of tree point cloud data. On field, it is measured by different instruments such as diameter tape and caliper. Tree height (Figure 2. c) was extracted by the difference in the value of zvalue of point cloud data. The tree height can vary when the terrain is undulating because there is variation in the observer's sight distance from the ground and it shows the varying height of the tree from different positions on the ground. It is very difficult to detect the exact height of the tree by TLS in dense vegetation because the top canopy is shadowed and overlapped by the lower canopy which does not allow the sensor to detect the upper canopy of the tree. Therefore in case of taller trees, sometimes TLS provides under-estimated values. Stem heighted (Figure 2. d) was computed by subtracting the crown height from the tree height. Here, crown height refers to that portion of the tree where the lion's share of the leafy part exists neglecting fewer branches existing at lesser heights. Figure 3 shows the linear relationship of field height and TLS derived height with R2 of 0.96 and $\%$ RMSE of 6.45 . The number of trees considered is 49 . The scatter plot was used for comparing the 
value of height of all the trees. Field height was measured by using Laser range finder which is based on the trigonometric principles of observer's viewing angle and distance from the target.

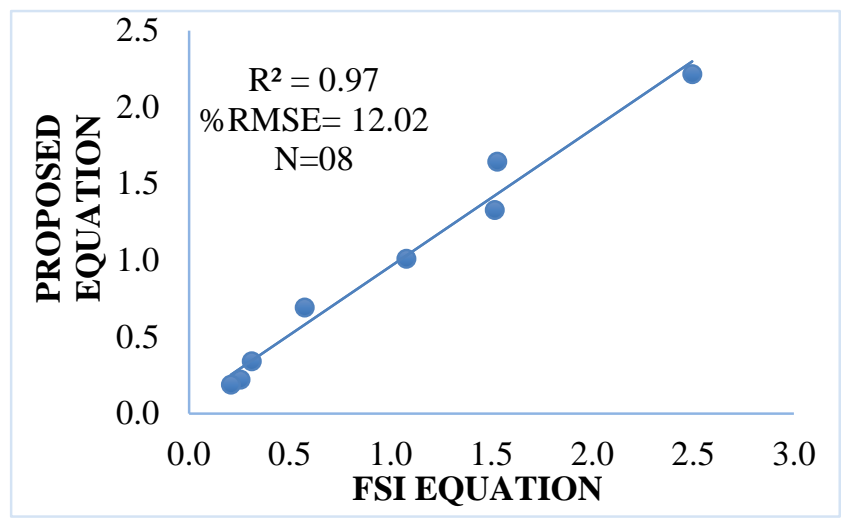

Figure 7. Comparison of Volume estimated through FSI equation \& Proposed equation for Teak.

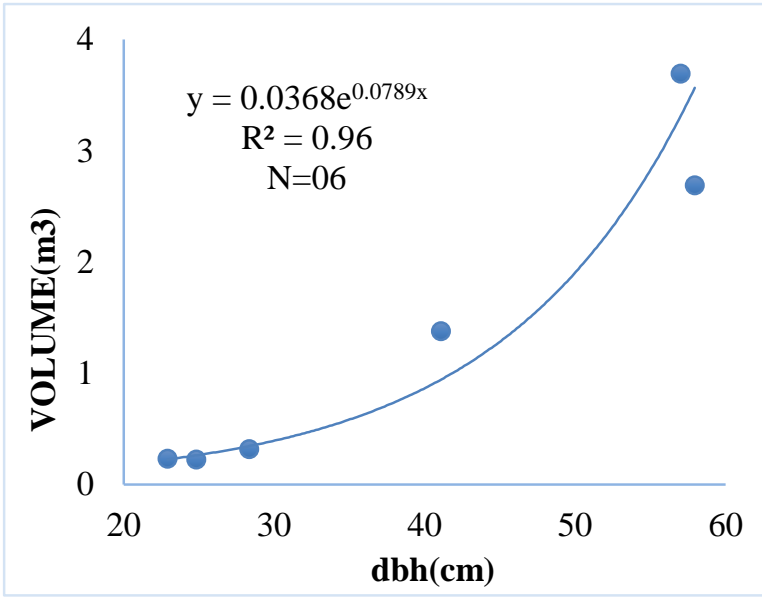

Figure 9. Scatter plot of dbh vs volume for Saj.

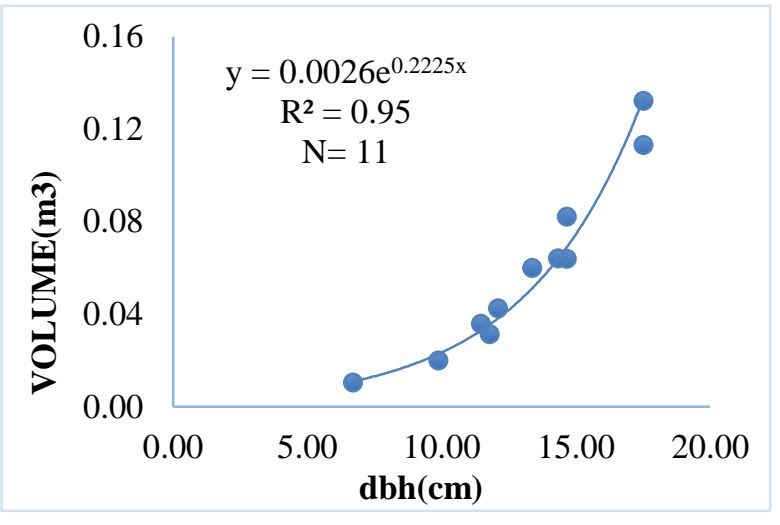

Figure 8. Scatter plot of dbh vs volume for Indian Red wood.

Table 2. Estimated volume using FSI (1996) and equation (i)

\begin{tabular}{|l|l|}
\hline FSI EQUATION & $\begin{array}{l}\text { PROPOSED } \\
\text { EQUATION }\end{array}$ \\
\hline 0.16 & 0.11 \\
\hline 0.04 & 0.03 \\
\hline 0.04 & 0.02 \\
\hline 0.08 & 0.06 \\
\hline-0.02 & 0.02 \\
\hline 0.07 & 0.06 \\
\hline 0.08 & 0.06 \\
\hline 0.05 & 0.04 \\
\hline 0.08 & 0.08 \\
\hline 0.04 & 0.04 \\
\hline 0.14 & 0.13 \\
\hline
\end{tabular}

Field dbh and TLS derived dbh were compared by using data of 49 trees. The scatter plot (Figure 4) shows positive high correlation value (R2) of 0.98 with \%R.M.S.E of 6.42. The variation in measure of dbh can be seen due to some reasons such as (i) measurement error gives different dbh measurements, (ii) due to variation in measurement from the different instruments such as measuring tape and tree calipers. The above discussed reasons for variation in measurement can be overcome by the use of TLS. There exists an inverse relationship between dbh and Form Factor as quite evident from Figure 5. The reason may be attributed to the fact that more the $\mathrm{dbh}$, more can be the variation in diameter of different segments of the tree trunk. Here, dbh less than $10 \mathrm{~cm}$ is not taken into account because it adds negligible biomass. As mentioned earlier, site specific (Barkot) volume equations for various tree species are not available. Moreover, there are no volume equations available corresponding to some 
tree species. In brief, the coefficients of the equations are species and site specific. Among the four tree species considered in this study, volume estimation equations developed by FSI (1996) corresponding to Barkot region are available for Sal and Teak. Volumetric equation is available for Indian Red Wood but it is meant to be used for Assam. Finally, there are no empirical equation available for the species Saj. The approach adopted in the present study for the tree volume estimation is:

$$
\mathrm{V}=\text { Form Factor* } \pi *(\mathrm{dbh} / 2)^{2 * \mathrm{~L}}
$$

equation (i)

Here V represents tree volume and L represents stem length.

The volume estimation equation for Shorea robusta (Sal) developed by FSI (1996) is:

$$
\mathrm{V}=0.03085-0.77794 * \mathrm{dbh}+8.42051 * \mathrm{dbh}^{2}+5.91067 * \mathrm{dbh}^{3}
$$

The equation takes into account only dbh. The present study considers three parameters: dbh, stem length and Form Factor. It should be noted that Form Factor has been computed based on the ratio of the diameter just below the crown to the diameter at breast height. Average Form Factor of Shorea robusta for the study area is 0.7 . Number of trees considered is 30. The scatter plot (Figure 6) shows positive high correlation value $\left(\mathrm{R}^{2}\right)$ of 0.98 with \%R.M.S.E of 11.53 between the estimated volumes with the two approaches. Again, the volume equation for Tectona grandis (Teak) developed by FSI (1996) is:

$$
\mathrm{V}=0.08847-1.46936 * \mathrm{dbh}+11.98979 * \mathrm{dbh}^{2}+1.97056 * \mathrm{dbh}^{2}
$$

Average Form Factor of Teak for the study area is 0.78 . Number of trees considered is 08 . The scatter plot (Figure 7) shows positive high correlation value (R2) of 0.97 with \%R.M.S.E of 12.02 between the estimated volumes with the two approaches. Next tree species considered in this study is Mallotus philippensis (Indian Red Wood). The volume equation developed by FSI (1996) particular to Assam is:

$$
\mathrm{V}=0.14749-2.87503 * \mathrm{dbh}+19.61977 * \mathrm{dbh}^{2}-19.1163 * \mathrm{dbh}^{3}
$$

However, this equation has been used extensively in other parts of the country including Barkot due to the unavailability of any equation specific to a particular area. As such, this equation may produce inaccurate or at times negative values. As such, with the present approach a new volume equation for Barkot region has been developed. The empirical equation takes dbh as input. The number of tree samples considered is 11. Exponential fit (Figure 8) has been used to derive the empirical equation which is as follows:

$$
\mathrm{V}=0.0026 \mathrm{e}^{0.2225 * \mathrm{dbh} \quad \text { equation (ii) }}
$$

The following table highlights the difference in volumetric values computed using FSI (1996) equation and with equation (i). An erroneous value of -0.02 (marked in red) stamps the emphasis of the volume equation specific to Barkot for Indian Red Wood. The final species considered in this study is Terminalia alata (Saj). The Barkot specific Form factor of this species is 0.68. There is no volume equation available for this species which has triggered the need for generating one in this present study. The number of tree samples considered is 06. Again exponential fit (Figure 9) is providing high correlation. The equation is:

$$
\mathrm{V}=0.0368 \mathrm{e}^{0.0789 *} \mathrm{dbh}
$$

equation (iii)

\section{Conclusions}

In the present study, TLS derived height and dbh showed excellent correlation with inventory parameters measured on field. Hence, it can be inferred that TLS can be used to measure the forest inventory parameters with very high accuracy. The fact that diameter at breast height is having an 
inverse relationship with the Form Factor is also confirmed from this present piece of work. The volume estimated for Sal and Teak with the proposed approach showed excellent correlation with the volume estimated through FSI (1996) equations. The given approach can be adopted for the volume estimation of tree species whose volume equations are not available. With the unavailability of site and species-specific volume equations, there are chances high inaccuracy associated with the estimated volume. The present approach may pave way to increased accuracy. However, the lack of samples leaves scope for further study with increased tree samplings. Moreover, the approach can be tested for more number of species and varied study areas in the time to come.

\section{References}

Andersson, K., T. P. Evans, and K. R. Richards. (2009). National Forest Carbon Inventories: Policy Needs and Assessment Capacity, Climatic Change 93(1-2), pp. 69-101.

Chave J, C Andalo , S. Brown , MA. Cairns, JQ. Chambers, D Eamus , H F€olster, F Fromard, N Higuchi, T Kira and J-P Lescure (2005). Tree allometry and improved estimation of carbon stocks and balance in tropical forests, Oecologia 145 (1), pp. 187-99.

Dassot, M., T. Constant and M. Fournier. (2011). The use of terrestrial LiDAR technology in forest science: application fields, benefits and challenges, Annals of Forest Science. 68(5), pp. 959-974.

Kushwaha, S. P.S., S. Nandy and M. Gupta (2014). Growing Stock and Woody Biomass Assessment in Asola-Bhatti Wildlife Sanctuary, Delhi, India, Environmental Monitoring and Assessment 186(9), pp. 5911-20.

Maan, Gurveek Singh., C. K. Singh, M. K. Singh, and Balaji Nagarajan. (2015). Tree Species Biomass and Carbon Stock Measurement Using Ground Based-LiDAR, Geocarto International 30(3), pp. 293 310.

Maas, H. G., A. Bienert, S. Scheller, and E. Keane (2008). Automatic Forest Inventory Parameter Determination from Terrestrial Laser Scanner Data, International Journal of Remote Sensing 29(5), pp. 1579-93.

Hopkinson, Chris, L. Chasmer, Colin Young-Pow and Paul Treitz (2004). Assessing Forest Metrics with a Ground-Based Scanning Lidar, Canadian Journal of Forest Research 34(3), pp. 573-83.

Lefsky, Michael A., W. B. Cohen, G. G. Parker and D. J. Harding (2002). BioOne Research Evolved, BioScience 52(1), pp. 19-30.

Mon, S.M., N Mizoue, N.Z. Htun, T. Kajisa and S. Yoshida (2012). Estimating forest canopy density of tropical mixed deciduous vegetation using Landsat data: a comparison of three classification approaches, International Journal of Remote Sensing, 33(4), pp. 1042-1057.

Pimentel, D., R. Zuniga, and Doug Morrison (2005). Update on the Environmental and Economic Costs Associated with Alien-Invasive Species in the United States, Ecological Economics 52(3), pp. 273-88. 
Raumonen, P., M. Kaasalainen, M. Akerblom, S. Kaasalainen, H. Kaartinen., M. Vastaranta, M Holopainen, M. Disney and P. Lewis (2013). Fast Automatic Precision Tree Models from Terrestrial Laser Scanner Data, Remote Sensing 5(2), pp. 491-520.

Siedel, D. Albert, K., C. Ammer, L. Fehrmann, and C. Kleinn (2013). Using TLS to support biomass estimation in densely stocked young tree plantations, International Journal of Remote Sensing 34(24), pp. 8699-8709.

Tansey, K., N. Selmes, A. Anstee, N.J. Tate and A. Denniss (2009). Estimating tree and stand variables in a Corsican Pine woodland from terrestrial laser scanner data, International Journal of Remote Sensing, 30(19), pp. 5195-5209. 